\title{
Response of Anatomical Structure to Soil Drought in Old P. kangdingensis Cuttings of Section Tacamahaca Spach
}

\author{
Yanyuan Lu 1, a, Fang Wang ${ }^{1, ~ b}$ and Li Pan ${ }^{2, c^{*}}$ \\ ${ }^{1}$ Key Laboratory of State Forestry Administration on Biodiversity Conservation in Southwest China, \\ Southwest Forestry University, Kunming, 650224, People's Republic of China \\ 2 Colleges of Accounting, Southwest Forestry University, Kunming Yunnan 650224, China \\ a376319089@qq.com, b35445230@qq.com, cdeschn@qq.com \\ * The corresponding author
}

\section{Keyword: P. kangdingensis; Old tree; Drought resistance; Anatomical structure}

\begin{abstract}
In this paper, the cutting seedlings of P. kangdingensis, which age of 300-500 years old and diameter at breast height $(\mathrm{DBH})$ was greater than $1 \mathrm{~m}$ were used as experimental materials, and the anatomical structure of the leaves and stems of seedlings were studied by the method of paraffin section. The pot experiment was conducted by way of weighing to control water content in soil, that was to weigh the pot in every afternoon and supplement the consumption of water to keep it about $60 \%$ of the maximum field water capacity, and the control was kept about $80 \%$ of that. The water control test lasted for about 3 months and plant tissues had changes in the physiological structure. Then, the samples were collected and measured by paraffin section method. The results showed that, under drought treatment, the thickness of palisade tissue and sponge tissue in the leaves of old P. kangdingensis cutting seedlings increased significantly, while the thickness of upper and lower epidermis, the cuticle, and the leaves thickness increased slightly. Besides, the structure of the transport tissue decreased significantly on the stem, indicating that in a certain degree of drought, the morphological and anatomical structures of P. kangdingensis could be adjust accordingly to adapted to drought and then have strong drought resistance.
\end{abstract}

\section{Introduction}

Poplar is characterized by wide distribution, strong adaptability, fast growth, easy breeding and wide use, so it also is considered as a good afforestation tree for papermaking, shelterbelt and short term rotation, and it has contributed significantly to forestry production and regional ecological management $[1,2]$. The geographical and climatic of Southwest China are complex and diverse, so that the genetic resources of Populus Cathay are very abundant and it is one of the natural distribution centers of poplar in China. Besides, the unique historical conditions also bring rich old poplar resources, which are the most authentic native tree species since they have survived for many years under the comprehensive effects of many ecological factors and human factors, and they are the best choice for afforestation to improve the local environment [3].

Plants growing in the arid environment usually gradually form a variety of drought resistant morphological and anatomical characteristics [4]. Among of them, leaf and stem structural features most reflect the adaptability of plants to the drought environment. Leaf is the main organ for plant to assimilate and transpiration, and stem is main transfusion tissue, both of them are the most sensitive organ to drought stress, and then they are important aspects of the comprehensive evaluation of plant drought resistance [5, 6]. Therefore, the measurement and analysis of representative tissue anatomical indices is an important aspect of plant drought resistance research.

Therefore, this experiment took the cutting seedlings of the old tree of P. kangdingensis as material, and the pot experiment was conducted by way of weighing to control water content in soil to study the effect of drought stress on the tissue anatomy of P. kangdingensis cutting seedlings, and then discuss the physiological mechanism of old poplar to adapt to drought in the long growth process. It would provide theoretical support for selection of tree species and improvement of 
ecological environment.

\section{Materials and Methods}

Plant Material and Cultured. In this experiment, the cutting seedlings of P. kangdingensis, which age of 300-500 years old and diameter at breast height (DBH) was greater than $1 \mathrm{~m}$ were used as experimental materials. The experiment was carried out in the automatic intelligent greenhouse in Southwest Forestry University. In the middle of October 2017, the branches which no diseases and pests, and growth uniformly were selected to cut into about $20 \mathrm{~cm}$ per segment, then soaking in water with a proper amount of rooting powder and carbendazim for 14 hours, and then planted in the pots which filled with the homogeneous red soil. The drought treatment was started when the segments sprouted. During the experiment, the pests and diseases were observed and prevented every 10 days.

Drought Treatment and Experimental Design. The experiment set up two water levels of drought treatment and sufficient water treatment (control). Soil water content of control and drought treatment was maintained at $80 \%$ and $60 \%$ of field water holding capacity, respectively. Pot weighing method was used to control the soil water content, that is to weigh in the afternoon and supplement the consumption of water to keep it at the water level and maintain it for about 3 months, and then the related the paraffin slice began to be sampling and measured.

Anatomical Structure Measurements. After drought treatment, 3-5 middle stems and 3-5 fully expanded leaves of the seedlings were cut and brought to the laboratory for fixation immediately. The fixed leaves and stems were undergoing the steps of alcohol dehydration, transparency, wax invasion, embedding, the slice by Leica (thickness $10 \sim 12 \mu \mathrm{m}$ ), staining by double red - Green double, and seal by neutral gum. And then, Olympu (sBX51) microscope was used to observe and select representative paraffin sections to take photographs and record the transverse section characteristics of the tissues. The thickness of the blade, sheet, palisade tissue, sponge tissue and the microtube column were measured with the OLYSIABio Report measurement software, and the average value of each record was calculated by 30 values.

leaf tissue structure Tightness $(\mathrm{CTR} \%)=($ palisade tissue thickness / blade thickness $) \times 100$

Leaf tissue structure porosity $(\mathrm{SR} \%)=($ spongy tissue thickness $/$ blade thickness $) \times 100$

\section{Statistical Analysis}

ANOVA was performed in a completely randomized design. Duncan's multiple range test was used in the mean separation of groups, and the results from this test are displayed as letters associated with the mean. All variable values are expressed as the mean \pm standard error of the mean (SE). The alpha level was set at 5\%. The statistical software SPSS17.0 was used.

\section{Results}

Effects of Drought Stress on Leaf Anatomical Structure of the Old Poplar Cutting. The leaves of P. kangdingensis are heterogeneous, and the leaf tissue is divided into upper epidermis cells, palisade tissue, sponge tissue and lower epidermis cells from top to bottom. Under microscope, it could be found that the palisade tissue cells were long cylindrical, closely arranged in 1-2 layers, and were stained deep, besides, rich chloroplasts also were observed. Spongy tissue was arranged in a loose irregular shape with large cell gap. The veins were well-developed, and the width of the main veins was not very different from the lateral veins. Comparison of the A and B in Fig. 2, we found that the structure of the full water supply was very full, but some of the tissue structures of the drought stress were not. In the view of the C and D in Fig. 1, the cells under the drought treatment was much scattered, the thickness of leaf, upper/lower epidermis, palisade tissue and cuticle were increased except spongy tissue. The difference was found to be significant in leaf thickness, palisade tissue and spongy tissue (table 1). Besides, the microstructure of the leaves (CTR \%) was slightly decreased, while the looseness of the tissue structure (SR \%) rose 
significantly, indicating that drought stress produces a large shadow on the anatomical structure of its leaves.
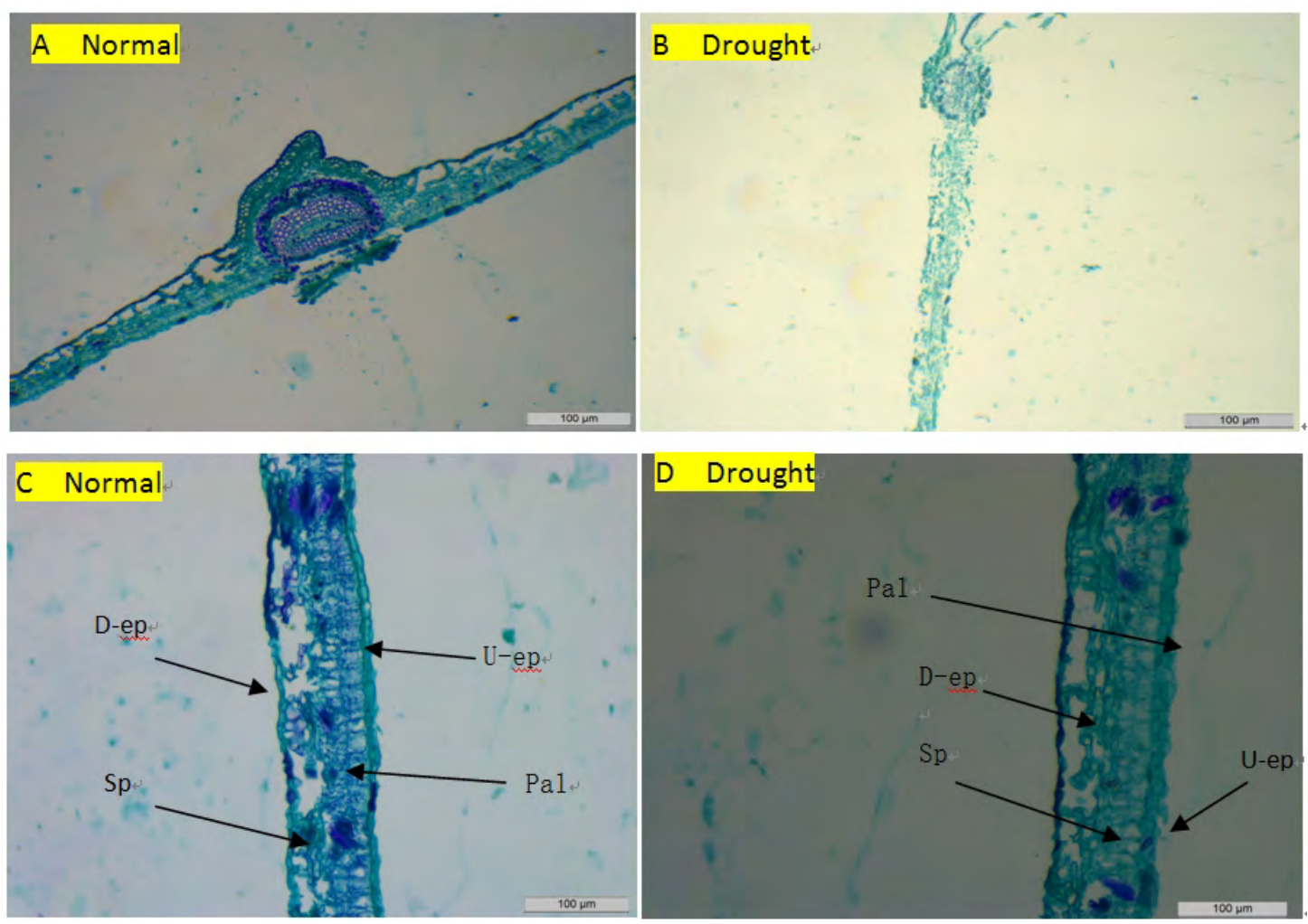

Figure 1. Finite Effects of drought stress on leaf anatomical structure of old poplar cutting Normal (A, C) and drought treatment (B, D)

U-ep: upper epidermis; D-ep: lower epidermis; Pal: palisade tissue; Sp: spongy tissue

Table1 Effects of drought stress on leaf anatomical structure of old poplar cutting

\begin{tabular}{lllllllll}
\hline & $\begin{array}{l}\text { leaf } \\
\text { thickness } \\
/ \boldsymbol{\mu m}\end{array}$ & $\begin{array}{l}\text { upper } \\
\text { epidermis } \\
/ \boldsymbol{\mu m}\end{array}$ & $\begin{array}{l}\text { lower } \\
\text { epidermis } \\
/ \boldsymbol{\mu m}\end{array}$ & $\begin{array}{l}\text { palisade } \\
\text { tissue } / \boldsymbol{\mu m}\end{array}$ & $\begin{array}{l}\text { spongy } \\
\text { tissue } / \boldsymbol{\mu m}\end{array}$ & $\begin{array}{l}\text { cuticle } \\
/ \boldsymbol{\mu m}\end{array}$ & $\begin{array}{l}\text { CTR } \\
\boldsymbol{\%}\end{array}$ & \multicolumn{2}{|c}{$\mathbf{S R} \%$} \\
\hline Normal & $173.02 \pm 0.75 \mathrm{~b}$ & $21.14 \pm 2.39 \mathrm{ab}$ & $17.69 \pm 1.28 \mathrm{ab}$ & $60.52 \pm 6.65 \mathrm{~b}$ & $96.88 \pm 2.96 \mathrm{a}$ & $2.81 \pm 0.33 \mathrm{ab}$ & $35.01 \mathrm{a}$ & $55.91 \mathrm{a}$ \\
$\begin{array}{l}\text { Drough } \\
\mathbf{t}\end{array}$ & $236.52 \pm 16.72 \mathrm{a}$ & $39.38 \pm 5.80 \mathrm{ab}$ & $23.39 \pm 1.57 \mathrm{a}$ & $81.59 \pm 6.02 \mathrm{a}$ & $79.40 \pm 2.95 \mathrm{~b}$ & $3.51 \pm 0.35 \mathrm{a}$ & $34.20 \mathrm{a}$ & $33.57 \mathrm{~b}$ \\
\hline
\end{tabular}

The data was measured observed with an optical microscope at a magnification of 10 times Different letters represent significant differences $(\mathrm{p}<0.05)$

Effects of Drought Stress on Stem Anatomical Structure of the Old Poplar Cutting. Under drought treatment, the pith, xylem, cambium, phloem and the bark were significantly reduced, and the pulp, xylem and bark were significantly different from those of the control (Fig. 2). In addition, in the view of microscope, it was found that intramedullary tissue was also reduced and xylem was contracted. The bark and the cambium also changed. The difference was found to be significant in xylem, cambium and bark (Table 2). 


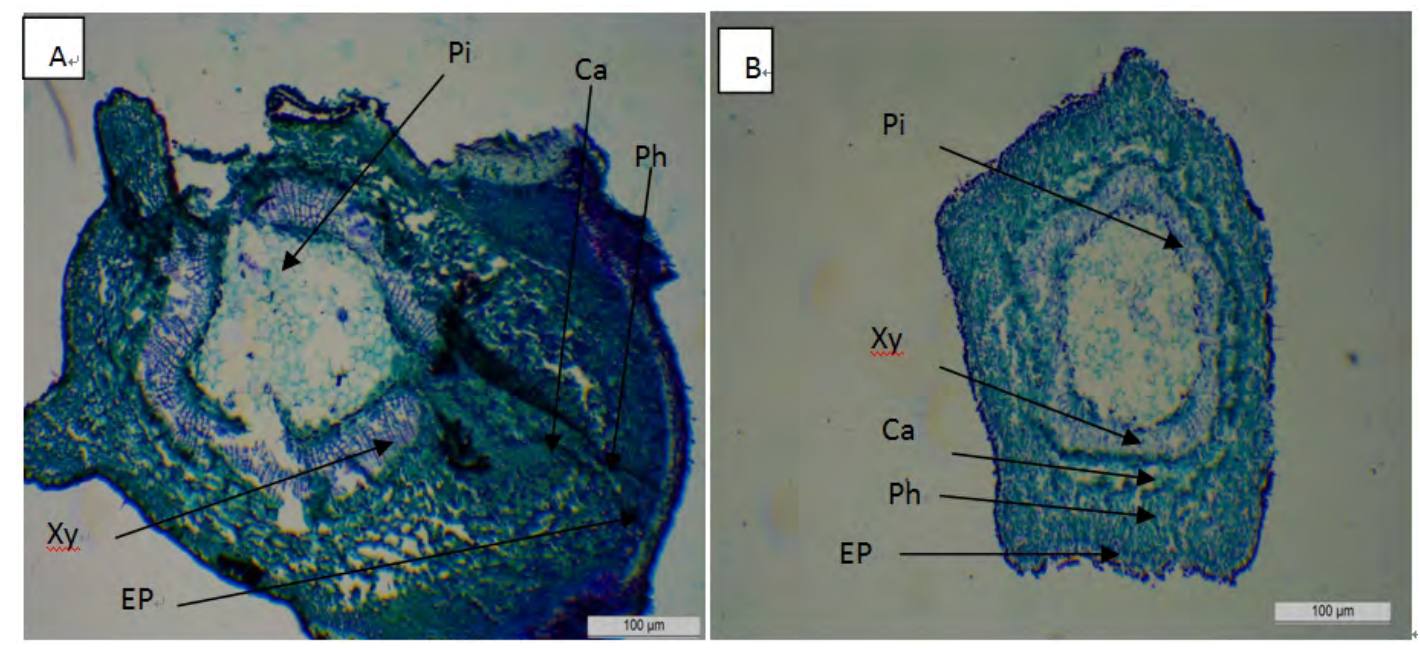

Figure 2. Finite Effects of drought stress on stem anatomical structure of old poplar cutting Normal (A) and drought treatment (B)

pi: pith; Xy: xylem; Ca: cambium; Ph: phloem; Ep: epiphloedal thichness

Table 2 Effects of drought stress on stem anatomical structure of old poplar cutting

\begin{tabular}{llllll}
\hline & $\begin{array}{l}\text { Pith diameter } \\
/ \boldsymbol{\mu m}\end{array}$ & $\begin{array}{l}\text { Xylem } \\
/ \boldsymbol{\mu m}\end{array}$ & $\begin{array}{l}\text { cambium } \\
/ \boldsymbol{\mu m}\end{array}$ & $\begin{array}{l}\text { phloem } \\
/ \boldsymbol{\mu m}\end{array}$ & $\begin{array}{l}\text { Bark } \\
/ \boldsymbol{\mu m}\end{array}$ \\
\hline Normal & $767.955 \pm 75.301 \mathrm{a}$ & $841.147 \pm 68.465 \mathrm{a}$ & $52.515 \pm 5.872 \mathrm{a}$ & $294.302 \pm 1.797 \mathrm{a}$ & $104.011 \pm 23.361 \mathrm{a}$ \\
Drought & $690.769 \pm 29.428 \mathrm{ab}$ & $213.352 \pm 23.34 \mathrm{~b}$ & $33.196 \pm 2.132 \mathrm{~b}$ & $209.488 \pm 11.905 \mathrm{ab}$ & $61.276 \pm 7.342 \mathrm{~b}$ \\
\hline
\end{tabular}

The data was measured observed with an optical microscope at a magnification of 4 times

Different letters represent significant differences $(\mathrm{p}<0.05)$

\section{Discussion}

Plants adaptability is the adaptation of plants to the external environment for a long time, which is not only related to their internal physiological activities and external conditions, but also depends on their own morphological and structural characteristics [7, 8]. Leaf and stem segments are the largest organs exposed to the environment [9]. They are most sensitive in the complex environment and are most easily adapted to the environment and change their morphology and structure.

The thickness of plant leaves can prevent the excessive evaporation of water in the plant, and it also has a strong refraction, which can prevent the burn caused by strong sunshine [10], so the thickness of the leaves would be increased under drought stress. The epidermal cells could store water, and the large cortical cells under the inner epidermal cells contain mucous substances, which has great advantage of keeping water. In the rainfall season, these aquiferous tissues can be filled with water to prepare for drought [11]. Under drought stress, the developed double palisade tissue was well developed, so the photosynthetic rate was greatly improved. While, the sponge tissue was relatively undeveloped, so that the lateral contact surface between the mesophyll cells was greatly reduced, and the transport of material in the blade was reduced in the horizontal direction accordingly. Therefore, the mesophyll transport tissue (vein) was particularly developed, forming a smaller net gap in the blade, which was helpful to solve to material's transportation problem in the horizontal direction in the blade.

The stem of the plant is connected with the upper branches and leaves and the lower roots. The main function is mechanical support and transport $[12,13]$. Under the drought stress, the water and nutrients absorbed by the root were reduced, and the photoassimilates contracted, so that the stems' conducting function decreased. Besides, the xylem, cambium, phloem and the bark thickness were reduced accordingly to reduce the evaporation and transpiration to adapt to the water deficit, and put more energy to resist the harm caused by the adversity. 


\section{Acknowledgments}

This research was supported by grants from the National Natural Science Foundation of China (31460181).

\section{Reference}

[1] C.E. Pan, LP Tian, ZZ Li, TY Zhang, PC Li , Studies on drought resistance on anatomical structure of leaves of 5 poplar clones, Chinese Agricultural Science Bulletin. 27 (2011) 2, 21-25. (in Chinses)

[2] K.S. Schumaker and M.A. Dietrich, Programmed changes in form during moss development. The Plant Cell, 9 (1997) 7, 1099-1107.

[3] H.S Yu, J. Liu, R.D. Fu, D.J. Liu, Y. Liu and Y.Q. L, Characteristics of tacamachaca genes in the western sichuan plateau. Journal of Zhejiang Forestry College, 20 (2003) 1, 27-31. (in Chinses)

[4] F.J. Zhang, K.K. Zhang, C.Z. Du, J. Li, Y.X. Xing, L.T. Yang and Y.R. Li, Effect of drought stress on anatomical structure and chloroplast ultrastructure in leaves of sugarcane, Sugar Tech, 17(2015) 1, 41-48.

[5] L.I.U. Qiu, L.I. Zhi and W.U. Ji, Research Progress on Leaf Anatomical Structures of Plants Under Drought Stress, Agricultural Science \& Technology, 17 (2016) 1: 4-14. (in Chinses)

[6] M. Haworth, M. Centritto, A. Giovannelli, G. Marino, N. Proietti, D. Capitani and F. Loreto, Xylem morphology determines the drought response of two Arundo donax ecotypes from contrasting habitats, Gcb Bioenergy, 9 (2017) 1, 119-131.

[7] J.C. Domec, D.D. Smith and K.A. McCulloh, A synthesis of the effects of atmospheric carbon dioxide enrichment on plant hydraulics: implications for whole-plant water use efficiency and resistance to drought, Plant, cell \& environment, 40 (2017) 6, 921-937.

[8] R. Gebauer, S.P. Vanbeveren, D. Volařík, R. Plichta and R. Ceulemans, Petiole and leaf traits of poplar in relation to parentage and biomass yield, Forest Ecology and Management, 362 (2016), $1-9$.

[9] X. Cao, J. Jia, C. Zhang, H. Li, T. Liu, X. Jiang, A. Polle, C.H. Peng and Z.B. Luo, Anatomical, physiological and transcriptional responses of two contrasting poplar genotypes to drought and re-watering, Physiologia plantarum, 151 (2014) 4, 480-494.

[10] C.J. Crous, I. Greyling and M.J. Wingfield, Dissimilar stem and leaf hydraulic traits suggest varying drought tolerance among co-occurring Eucalyptus grandis $\times$ E. urophylla clones, Southern Forests: a Journal of Forest Science, 80 (2018) 2, 175-184.

[11] H. Zheng, X. Zhang, W. Ma, J. Song, S.U. Rahman, J. Wang and Y. Zhang, Morphological and physiological responses to cyclic drought in two contrasting genotypes of Catalpa bungei, Environmental and Experimental Botany, 138 (2017), 77-87.

[12] A.M. Almeida-Rodriguez, J.E. Cooke, F. Yeh and J.J. Zwiazek, Functional characterization of drought-responsive aquaporins in Populus balsamifera and Populus simonii $\times$ balsamifera clones with different drought resistance strategies, Physiologia Plantarum, 140 (2010)4, 321-333.

[13] S.G. Schreiber, U.G. Hacke, A. Hamann and B.R. Thomas, Genetic variation of hydraulic and wood anatomical traits in hybrid poplar and trembling aspen, New Phytologist, 190 (2011) 1, 150-160. 